\title{
Início de florescimento, produção e valor nutritivo de gramíneas forrageiras tropicais sob condição de sombreamento natural(1)
}

\begin{abstract}
Margarida Mesquita Carvalho( ${ }^{(2)}$, Vicente de Paula Freitas ${ }^{(3)}$ e Deise Ferreira Xavier ${ }^{(2)}$
Resumo - Um experimento foi conduzido para estudar seis gramíneas forrageiras tropicais quanto ao seu valor nutritivo, florescimento, e produção de matéria seca quando sombreadas por árvores de angico-vermelho (Anadenanthera macrocarpa). Foram estudadas as gramíneas Brachiaria brizantha cv. Marandu, Panicum maximum cvs. Aruana, Makueni, Mombaça e Tanzânia e Cynodon dactylon cv. Tifton 68. O desempenho das gramíneas sob as árvores foi comparado com o obtido em área próxima, sem árvores (controle). O sombreamento retardou o início do florescimento de todas as gramíneas, em maior ou menor grau, dependendo da espécie. A produção de matéria seca das gramíneas foi reduzida pelo sombreamento, exceto no corte 3 , no qual o crescimento nas áreas com e sem sombra não diferiu significativamente. O Tifton 68 não tolerou as condições de sombreamento, e as outras espécies tiveram tolerância moderada. As concentrações de $\mathrm{N}$ nas folhas de todas as gramíneas aumentaram significativamente na área de sombra em relação à área de sol. Nas condições de sombreamento, a DIVMS da parte aérea total das gramíneas foi significativamente mais alta do que na área sem árvores.
\end{abstract}

Termos para indexação: matéria seca, nitrogênio, tolerância à sombra, valor nutritivo.

\section{Initial flowering, dry matter yield and nutritive value of tropical forage grasses under natural shading}

\begin{abstract}
An experiment was undertaken to study six different species of tropical forage grasses as their nutritive value, flowering and dry matter production when under the shade of Anadenanthera macrocarpa trees. The grasses Brachiaria brizantha cv. Marandu, Panicum maximum cvs. Aruana, Makueni, Mombaça and Tanzânia, and Cynodon dactylon cv. Tifton 68 were studied. Grass performance under trees was compared to that in a nearby area in full sunlight (check). Shade delayed the initial flowering of all grasses, to a variable degree depending on the species. Grass dry matter yield was reduced by shade, except in harvest 3, where grass growth did not differ between treatments. Tifton 68 was not tolerant to shade and the other grasses exhibited moderate tolerance. The $\mathrm{N}$ concentrations in the leaves of all grasses increased significantly under shade in comparison to the full sunlight condition. Similarly, the IVDMD of the whole plants increased under shade condition.
\end{abstract}

Index terms: dry matter, nitrogen, shade tolerance, nutritive value.

\section{Introdução}

A utilização de forrageiras tolerantes ao sombreamento é uma das condições necessárias para se obter as vantagens potenciais da associação de

(1) Aceito para publicação em 6 de agosto de 2001 . Parcialmente financiado pela Fapemig.

(2) Embrapa-Centro Nacional de Pesquisa de Gado de Leite, Rua Eugênio do Nascimento, 610, CEP 36038-330, Juiz de Fora, MG. Bolsista do CNPq

E-mail: mmcarval@cnpgl.embrapa.br, dfxavier@cnpgl.embrapa.br

(3) Embrapa-Centro Nacional de Pesquisa de Gado de Leite, Campo Experimental de Coronel Pacheco, Rodovia MG 133, km 42, CEP 36155-000 Coronel Pacheco, MG pastagens cultivadas com árvores (Carvalho, 1998). De acordo com Wong (1991), essa característica se refere à capacidade da espécie de crescer à sombra em relação ao crescimento a pleno sol, e sob a influência de desfolhações regulares. Além do crescimento, outros aspectos importantes das gramíneas forrageiras que podem ser afetados pelo sombreamento são o florescimento, e conseqüentemente, a produção de sementes, e aspectos do valor nutritivo da forragem, como digestibilidade e composição mineral.

A tolerância ao sombreamento varia entre espécies de gramíneas e de leguminosas forrageiras (Wong, 1991; Castro et al., 1999). Entre as gramíneas, alguns acessos e cultivares da espécie Panicum maximum 
têm geralmente exibido boa tolerância, tanto nos experimentos feitos com sombra artificial (Wong \& Wilson, 1980; Castro et al., 1999), como nos feitos com sombra natural (Carvalho et al., 1997; Bustamante et al., 1998). No entanto, diversas cultivares dessa espécie têm sido lançadas mais recentemente, a maioria com grande importância como forrageira, tornando-se portanto desejável conhecer a sua tolerância ao sombreamento.

O objetivo do presente trabalho foi estudar algumas gramíneas forrageiras tropicais quanto ao seu valor nutritivo, florescimento e produção de matéria seca quando influenciadas pela sombra de árvores.

\section{Material e Métodos}

O trabalho foi realizado no Campo Experimental de Coronel Pacheco, MG, pertencente à Embrapa-Centro Nacional de Pesquisa de Gado de Leite, em área de Latossolo Vermelho-Amarelo, localizada em terreno de topografia acidentada. O Município de Coronel Pacheco está situado a $21^{\circ} 33^{\prime} 22^{\prime \prime}$ de latitude Sul e $43^{\circ} 6^{\prime} 15^{\prime \prime}$ de longitude Oeste, com altitude de 426 metros. A precipitação pluvial média anual é de $1.600 \mathrm{~mm}$; cerca de $90 \%$ desse total ocorre nos meses de outubro a abril.

Os tratamentos testados foram seis gramíneas, com e sem o efeito de sombreamento. Adotou-se o delineamento experimental de blocos ao acaso, com os tratamentos arranjados em fatorial e quatro repetições. As gramíneas estudadas foram: Brachiaria brizantha cv. Marandu, Panicum maximum cvs. Aruana, Makueni, Mombaça e Tanzânia e Cynodon dactylon cv. Tifton 68. Com o efeito do sombreamento: a) sombra de árvores da espécie angico-vermelho (Anadenanthera macrocarpa (Benth) Brenen), e b) sem sombra (controle). As árvores, plantadas com espaçamento de $7 \times 7 \mathrm{~m}$ há mais de 30 anos, estão hoje em densidade suficiente para reduzir a porcentagem de transmissão de luz ao longo do ano para 30-60\% da luz incidente em área adjacente sem árvores. Antes da instalação do experimento, foram coletadas amostras de solo $(0-20 \mathrm{~cm})$, e obtiveram-se os seguintes resultados: $\mathrm{pH}$ em água, 4,35 e 4,60; P (Mehlich 1), 3,81 e 4,07 mg/dm ${ }^{3}$; e cátions trocáveis em $\mathrm{cmol}_{\mathrm{c}} / \mathrm{dm}^{3}$ : Ca, 0,23 e 0,$99 ; \mathrm{Mg}, 0,16$ e 0,$22 ; \mathrm{K}, 0,16$ e 0,12 e Al, 1,67 e 0,46 , nas áreas com e sem árvores, respectivamente.

O plantio foi realizado em $9 / 3 / 95$, em parcelas de $3 \times 2 \mathrm{~m}$, marcadas entre as fileiras de árvores. Um mês antes do plantio aplicaram-se 2 t/ha de calcário dolomítico na área sem árvores e $3 \mathrm{t} / \mathrm{ha}$ na área com árvores. Por ocasião do plantio aplicaram-se $100 \mathrm{~kg} / \mathrm{ha}$ de $\mathrm{P}_{2} \mathrm{O}_{5}$ (superfosfato simples) e $60 \mathrm{~kg} / \mathrm{ha}$ de $\mathrm{K}_{2} \mathrm{O}$ (cloreto de potássio). Em 8/10/96 aplicaram-se em cobertura, $40 \mathrm{~kg} / \mathrm{ha}$ de $\mathrm{P}_{2} \mathrm{O}_{5}$ e de $\mathrm{K}_{2} \mathrm{O}$, usando-se as mesmas fontes de adubo.

Após o estabelecimento das gramíneas, foram realizados quatro cortes, a $10 \mathrm{~cm}$ do solo, em 13/3/96, 22/5/96, 4/12/96 e 28/1/97, para avaliação da produção de matéria seca. Antes do primeiro e terceiro cortes, foram feitos cortes de uniformização, em 15/12/95 e 1/10/96, respectivamente. Em todos eles foram coletadas amostras de folhas verdes para a determinação da concentração de $\mathrm{N}$, pelo método de Kjeldahl. Por ocasião do corte de 4/12/96, foram coletadas amostras da parte aérea para determinação de fibra em detergente neutro (FDN) pelo método Soest (1963) e digestibilidade in vitro da matéria seca (DIVMS), pelo método Tilley \& Terry (1963).

Em janeiro de 1997, antes do quarto corte, e em abril do mesmo ano, foram feitas observações sobre o florescimento das gramíneas, anotando-se em cada data de observação e em cada parcela, as seguintes condições: ausência de florescimento, início do florescimento, representado pela presença da folha-bandeira, e florescimento. Apenas em uma das datas de observação (27/1/97) foi feita a contagem do número de inflorescências por parcela, usando-se dois quadrantes de $0,5 \mathrm{~m}^{2}$ por parcela.

Os dados de produção de matéria seca e composição química da forragem foram submetidos à análise de variância, utilizando-se o pacote estatístico SAEG (Euclydes, 1983?).

\section{Resultados e Discussão}

As observações sobre o florescimento foram feitas apenas para indicar o seu início nas gramíneas, sem quantificar o número de inflorescências ou medir a produção de sementes. O sombreamento retardou o início do florescimento de todas as gramíneas, em maior ou menor grau dependendo da espécie. Na primeira observação, feita no início de janeiro de 1997, o sombreamento havia retardado o florescimento das cultivares Aruana e Makueni, porém, já em 17/1 havia inflorescências em todas as parcelas dessas cultivares (Tabela 1). Na B. brizantha cv. Marandu, o efeito do sombreamento sobre o início do florescimento foi mais prolongado, manifestando-se nas quatro observações efetuadas. Nesse período, as cultivares Mombaça e Tanzânia não floresceram, mesmo na área sem árvores.

No segundo período de observações, em abril de 1997, as cultivares Aruana e Makueni confirmaram 
seu florescimento mais precoce em relação às outras duas cultivares de $P$. maximum incluídas no experimento, e também sua maior tolerância à sombra quanto ao florescimento (Tabela 1). A cv. Marandu não chegou a emitir inflorescências nas parcelas sombreadas, observando-se apenas a presença de folhas bandeiras na última avaliação (25/4/97), embora na área de sol houvesse inflorescências em todas as parcelas, durante todo o período. As cultivares Mombaça e Tanzânia floresceram nas parcelas sem sombra, porém, somente na última observação do período verificou-se a presença de inflorescências. Nas parcelas sombreadas, o florescimento dessas cultivares foi retardado, principalmente na cv. Tanzânia (Tabela 1).

O efeito do sombreamento retardando o início do florescimento em gramíneas poderia estar relacionado com o crescimento vegetativo mais prolongado das plantas sob essas condições. Ovalle \& Avendaño (1994) observaram um retardamento em todas as fases fenológicas de gramíneas e leguminosas sob cobertura de $80 \%$ com árvores de Acacia caven em relação às plantas das áreas sem árvores. No entanto, o sombreamento também contribuiu para reduzir a produção de sementes em gramíneas, conforme Oli- veira \& Humphreys (1986). Na contagem de inflorescências feita em 27/1/97, os valores obtidos nas cultivares Aruana, Makueni e Marandu, nos tratamentos sombra e sol, foram, respectivamente, 10,5 e 29,5; 2,0 e 9,7; e 1,2 e 6,0 inflorescências $/ \mathrm{m}^{2}$, sugerindo que a produção de sementes também poderá ser afetada.

Castro \& Carvalho (2000) observaram também redução na densidade média de inflorescências $\left(\mathrm{n}-/ \mathrm{m}^{2}\right)$ em B. brizantha cv. Marandu, B. decumbens, P. maximum cv. Vencedor e Andropogon gayanus cv. Planaltina, em condições de sombreamento artificial (0, 30 e 60\%). Porém, nesse estudo a densidade média de inflorescências aumentou em Setaria sphacelata.

A produção de matéria seca (MS) das gramíneas foi reduzida significativamente $(\mathrm{P}<0,01)$ no tratamento com sombra de árvores em relação à obtida a pleno sol, exceto no corte 3 (Tabela 2). No entanto, houve diferença entre as espécies quanto à resposta ao sombreamento, principalmente nos cortes 1 e 2 .

O Tifton cv. 68 não foi tolerante à sombra, não se adaptou às condições ambientais prevalecentes no experimento, e não persistiu após o corte 2 , mesmo na ausência de sombreamento. Na região, essa culti-

Tabela 1. Efeito do sombreamento sobre o início do florescimento de cinco gramíneas em janeiro e abril de $1997^{(1)}$.

\begin{tabular}{|c|c|c|c|c|c|c|c|c|c|c|c|c|c|}
\hline \multirow[t]{2}{*}{ Gramíneas } & \multirow[t]{2}{*}{ Tratamento } & \multicolumn{3}{|c|}{ 9/1/97 } & \multicolumn{3}{|c|}{$17 / 1 / 97$} & \multicolumn{3}{|c|}{ 21/1/97 } & \multicolumn{3}{|c|}{ 27/1/97 } \\
\hline & & SF & FB & CI & SF & FB & $\mathrm{CI}$ & SF & FB & $\mathrm{CI}$ & SF & FB & $\mathrm{CI}$ \\
\hline \multirow[t]{2}{*}{ Aruana } & Sol & - & - & 100 & - & - & 100 & - & - & 100 & - & - & 100 \\
\hline & Sombra & 25 & 25 & 50 & - & - & 100 & - & - & 100 & - & - & 100 \\
\hline \multirow[t]{2}{*}{ Makueni } & Sol & - & - & 100 & - & - & 100 & - & - & 100 & - & - & 100 \\
\hline & Sombra & - & 25 & 75 & - & - & 100 & - & - & 100 & - & - & 100 \\
\hline \multirow[t]{2}{*}{ Mombaça } & Sol & 100 & - & - & 100 & - & - & 100 & - & - & 100 & - & - \\
\hline & Sombra & 100 & - & - & 100 & - & - & 100 & - & - & 100 & - & - \\
\hline \multirow[t]{2}{*}{ Tanzânia } & Sol & 100 & - & - & 100 & - & - & 100 & - & - & 100 & - & - \\
\hline & Sombra & 100 & - & - & 100 & - & - & 100 & - & - & 100 & - & - \\
\hline \multirow[t]{4}{*}{ Marandu } & Sol & - & 100 & - & - & - & 100 & - & - & 100 & - & - & 100 \\
\hline & Sombra & 75 & 25 & - & 25 & 75 & - & 25 & 25 & 50 & - & 25 & 75 \\
\hline & & \multicolumn{3}{|c|}{$7 / 4 / 97$} & \multicolumn{3}{|c|}{$14 / 4 / 97$} & \multicolumn{3}{|c|}{$18 / 4 / 97$} & \multicolumn{3}{|c|}{$25 / 4 / 97$} \\
\hline & & SF & FB & $\mathrm{CI}$ & SF & FB & CI & SF & FB & $\mathrm{CI}$ & SF & FB & $\mathrm{CI}$ \\
\hline \multirow[t]{2}{*}{ Aruana } & Sol & - & - & 100 & - & - & 100 & - & - & 100 & - & - & 100 \\
\hline & Sombra & 75 & - & 25 & 25 & - & 75 & - & - & 100 & - & - & 100 \\
\hline \multirow[t]{2}{*}{ Makueni } & Sol & - & - & 100 & - & - & 100 & - & - & 100 & - & - & 100 \\
\hline & Sombra & - & 50 & 50 & - & - & 100 & - & - & 100 & - & - & 100 \\
\hline \multirow[t]{2}{*}{ Mombaça } & Sol & 100 & - & - & - & 100 & - & - & 100 & - & - & - & 100 \\
\hline & Sombra & 100 & - & - & 100 & - & - & 100 & - & - & 25 & 50 & 25 \\
\hline \multirow[t]{2}{*}{ Tanzânia } & Sol & 100 & - & - & 100 & - & - & - & 100 & - & - & - & 100 \\
\hline & Sombra & 100 & - & - & 100 & - & - & 100 & - & - & 75 & 25 & - \\
\hline \multirow[t]{2}{*}{ Marandu } & Sol & - & - & 100 & - & - & 100 & - & - & 100 & - & - & 100 \\
\hline & Sombra & 100 & - & - & 100 & - & - & 100 & - & - & - & 100 & - \\
\hline
\end{tabular}

(1)Porcentagem de parcelas nas seguintes condições: SF: sem florescimento; FB: presença de folha-bandeira; CI: com inflorescências. 
var tem sido recomendada para formação de piquetes em solo mais fértil, em área mecanizável, com manejo intensivo incluindo adubação nitrogenada e irrigação. Na literatura não foram encontradas referências à tolerância de Cynodon dactylon ao sombreamento em comparação com outras espécies, porém, há informações sobre outras espécies do gênero. De acordo com Wong (1991), a espécie C. plectostachyus apresenta baixa tolerância. No entanto, em estudos nos quais as árvores são podadas periodicamente, adicionando biomassa à pastagem, os resultados obtidos com espécies do gênero Cynodon têm sido diferentes. Na Colômbia, o capim-estrela (C. plectostachyus) produziu cerca de $40 \%$ mais MS em associação com Leucaena leucocephala e Prosopis juliflora do que em monocultura (Mahecha et al., 1999). A espécie C. nlemfuensis teve produção total de MS 50\% maior quando associada com Erythrina poeppigiana do que em área sem árvores (Bustamante et al., 1998).

A $B$. brizantha cv. Marandu e as cultivares de P. maximum tiveram comportamento semelhante, com tolerância média ao sombreamento, todas experimentando redução significativa de crescimento na área sombreada, exceto no corte 3 (Tabela 2). O desempenho relativamente fraco dessas cultivares na área sombreada está relacionado principalmente com a baixa luminosidade incidente no verão
( $40 \%$ de transmissão de luz), uma vez que, em outros estudos, essas espécies apresentaram tolerância média a alta (Wong \& Wilson, 1980; Carvalho et al., 1997; Bustamante et al., 1998; Castro et al., 1999). Contudo, no corte 3, as cvs. Marandu e Mombaça chegaram a produzir, respectivamente, $30 \%$ e $14 \%$ mais MS na sombra do que no sol, embora sem diferença significativa. No entanto, essa resposta parece mais relacionada com o mais baixo crescimento das gramíneas na área de sol, em comparação com o observado nos outros cortes. O período de crescimento que antecedeu o corte 3 , que abrangeu os meses de outubro e novembro de 1996, teve precipitação pluvial total de $353 \mathrm{~mm}$. No período seguinte (corte 4), a recuperação das gramíneas na área de sol pode estar relacionada com a precipitação total de $702 \mathrm{~mm}$

$\mathrm{Na}$ área sob as copas das árvores, o crescimento das gramíneas pode ter sido limitado também por mudanças na qualidade da luz, ou por competição por água pelas árvores, entre outros fatores. Na prática, não se recomenda densidade de árvores tão elevada como no presente estudo, esperando-se melhor desempenho dessas cultivares de gramíneas em sistemas silvipastoris.

Em todos os cortes, as concentrações de $\mathrm{N}$ nas folhas das gramíneas da área sombreada foram significativamente $(\mathrm{P}<0,01)$ mais altas do que nas fo-

Tabela 2. Produção de matéria seca (kg/ha) e concentração de nitrogênio nas folhas verdes de seis gramíneas forrageiras, em área com sombreamento por angico-vermelho e a pleno sol, em quatro épocas de avaliação( ${ }^{(1)}$.

\begin{tabular}{|c|c|c|c|c|c|c|c|c|}
\hline \multirow[t]{2}{*}{ Gramíneas } & \multicolumn{2}{|c|}{ Corte 1} & \multicolumn{2}{|c|}{ Corte 2} & \multicolumn{2}{|c|}{ Corte 3} & \multicolumn{2}{|c|}{ Corte 4} \\
\hline & Sol & Sombra & Sol & Sombra & Sol & Sombra & Sol & Sombra \\
\hline & \multicolumn{8}{|c|}{ Matéria seca $(\mathrm{kg} / \mathrm{ha})$} \\
\hline Marandu & 7.061 & $3.054(43)^{(2)}$ & 2.772 & $1.061(38)$ & 1.826 & $2.377(130)$ & 2.986 & $1.761(59)$ \\
\hline Aruana & 4.480 & $765(17)$ & 1.268 & $441(35)$ & 1.533 & $1.314(86)$ & 2.417 & $1.046(43)$ \\
\hline Makueni & 7.686 & $2.392(31)$ & 2.076 & 764 (37) & 1.637 & $1.594 \quad(97)$ & 3.199 & $1.566(49)$ \\
\hline Mombaça & 10.464 & $3.934(37)$ & 4.381 & $1.546(35)$ & 2.496 & $2.851(114)$ & 4.293 & $2.064(48)$ \\
\hline Tanzânia & 7.951 & $3.054(38)$ & 2.362 & $836(35)$ & 2.076 & $1.925 \quad(93)$ & 2.951 & $2.034(69)$ \\
\hline Tifton 68 & 4.022 & $92(2)$ & 1.112 & $63(6)$ & - & - & - & - \\
\hline $\mathrm{F}$ & $* *$ & & $* *$ & & ns & & *** & \\
\hline \multirow[t]{2}{*}{$\mathrm{CV}(\%)$} & 34,2 & & 38,4 & & 25,0 & & 25,4 & \\
\hline & \multicolumn{8}{|c|}{ Concentração de nitrogênio $(\mathrm{g} / \mathrm{kg})$} \\
\hline Marandu & 10,0 & 20,9 & 14,7 & 22,8 & 12,7 & & 12,9 & 23,5 \\
\hline Aruana & 13,8 & 25,3 & 18,1 & 27,5 & 17,0 & 23,3 & 14,0 & 25,8 \\
\hline Makueni & 11,9 & 21,8 & 14,4 & 25,2 & 16,0 & 23,9 & 12,0 & 22,7 \\
\hline Mombaça & 11,0 & 19,7 & 14,0 & 24,8 & 13,5 & 19,0 & 10,9 & 23,3 \\
\hline Tanzânia & 10,8 & 20,1 & 13,9 & 20,3 & 12,2 & 20,5 & 10,4 & 22,0 \\
\hline Tifton 68 & 13,8 & - & 14,7 & 24,1 & - & - & - & - \\
\hline $\mathrm{F}$ & $* *$ & & $* *$ & & $* *$ & & ** & \\
\hline $\mathrm{CV}(\%)$ & 10,6 & & 7,41 & & 10,0 & & 7,2 & \\
\hline
\end{tabular}

${ }^{(1)}$ Datas dos cortes: corte 1, 13/3/96; corte 2, 22/5/96; corte 3, 4/12/96; corte 4, 28/1/97. ${ }^{(2)}$ Números entre parênteses (\%): crescimento na sombra em

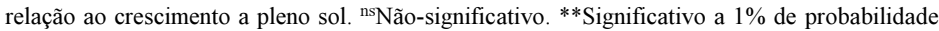


lhas das plantas crescidas sem sombra (Tabela 2). Embora possa ser sugerido um efeito de concentração desse elemento nas folhas das plantas sombreadas, em vista da menor produção de matéria seca na área com árvores (Tabela 2), há, na literatura, relatos sobre aumento simultâneo no crescimento e na concentração de $\mathrm{N}$ nas plantas sombreadas (Wong \& Wilson, 1980; Eriksen \& Whitney, 1981; Samarakoon et al., 1990). Além disso, no corte 3, as cultivares Mombaça e Marandu tiveram crescimento maior à sombra (Tabela 2), porém, as concentrações de $\mathrm{N}$ nas folhas foram 13,5 e 19,0 g/ kg para a primeira e 12,7 e $20,9 \mathrm{~g} / \mathrm{kg}$ para a segunda, no sol e sombra, respectivamente (Tabela 2 ).

$\mathrm{O}$ efeito médio dos tratamentos (sol e sombra) sobre a DIVMS foi significativo $(\mathrm{P}>0,01)$, com maior digestibilidade na parte aérea das gramíneas na área sombreada, exceto na cv. Tanzânia, que não apresentou diferença na DIVMS entre tratamentos (Tabela 3). Já os teores de FDN na parte aérea das gramíneas não foram afetados pelo sombreamento. Os aumentos médios na DIVMS, que variaram de $5 \%$ a 14\%, diferiram de alguns dos resultados disponíveis na literatura em outras cultivares dessas espécies. Castro (1996), em ensaio de campo, feito em solo de baixa fertilidade, usando sombra artificial, verificou que o sombreamento $(0,30$ e $60 \%)$ reduziu significativamente a DIVMS de folhas e caules das espécies B. brizantha cv. Marandu e P. maximum cv. Vencedor. Em outro ensaio de campo com sombra artificial, Wilson \& Wong (1982) observaram também queda na digestibilidade de $P$. maximum (green panic) com o aumento no nível de sombreamento.

Tabela 3. Fibra em detergente neutro (FDN) e digestibilidade in vitro da matéria seca (DIVMS) da parte aérea de cinco gramíneas forrageiras, em área com sombreamento natural e a pleno sol, em amostras da quarta época de avaliação ${ }^{(1)}$.

\begin{tabular}{lccccc}
\hline Gramíneas & \multicolumn{2}{c}{ FDN $(\%)$} & & \multicolumn{2}{c}{ DIVMS (\%) } \\
\cline { 2 - 3 } \cline { 5 - 6 } & Sol & Sombra & & Sol & Sombra \\
\hline Marandu & 73,92 & 73,12 & & 52,73 & 59,01 \\
Aruana & 72,97 & 78,02 & & 53,28 & 60,93 \\
Makueni & 76,05 & 76,17 & & 51,21 & 54,58 \\
Mombaça & 76,53 & 78,23 & & 50,69 & 53,35 \\
Tanzânia & 76,18 & 75,48 & & 55,83 & 55,75 \\
\hline F & ns & & $* *$ \\
\hline CV $(\%)$ & 6,4 & & 6,7 \\
\hline
\end{tabular}

(1)Data do corte: $4 / 12 / 96$. ns Não-significativo. ${ }^{* *}$ Significativo a $1 \%$ de probabilidade.

\section{Conclusões}

1. A tolerância ao sombreamento difere entre as gramíneas: o C. dactylon cv. Tifton 68 não é tolerante, e as outras espécies apresentam tolerância moderada.

2. O sombreamento retarda o início do florescimento nas cultivares Aruana, Makueni, Mombaça, Tanzânia e Marandu.

3. O valor nutritivo das gramíneas é favorecido pelo sombreamento natural de angico-vermelho, mesmo quando não há redução no crescimento.

\section{Referências}

BUSTAMANTE, J.; IBRAHIM, M.; BEER, J. Evaluación agronómica de ocho gramíneas mejoradas en un sistema silvopastoril con poro (Erythrina poeppigiana) en el trópico húmedo de Turrialba. Agroforestería en las Américas, Turrialba, v. 5, n. 19, p. 11-16, 1998.

CARVALHO, M. M. Efeito do sombreamento na produtiviade e na qualidade da forragem em pastagens. In: CONGRESSO BRASILEIRO DE BIOMETEOROLOGIA, 2., 1998, Goiânia. Anais... Goiânia: Sociedade Brasileira de Biometeorologia, 1998. p. 99-117.

CARVALHO, M. M.; SILVA, J. L. O.; CAMPOS JÚNIOR, B. A. Produção de matéria seca e composição mineral da forragem de seis gramíneas tropicais estabelecidas em um sub-bosque de angico-vermelho. Revista Brasileira de Zootecnia, Viçosa, MG, v. 26, n. 2, p. 213-218, 1997.

CASTRO, C. R. T. Tolerância de gramíneas forrageiras tropicais ao sombreamento. 1996. $245 \mathrm{f}$. Tese (Doutorado) - Universidade Federal de Viçosa, Viçosa.

CASTRO, C. R. T.; CARVALHO, M. M. Florescimento de gramíneas forrageiras cultivadas sob luminosidade reduzida. Ciência Rural, Santa Maria, v. 30, n. 1, p. 163166, 2000.

CASTRO, C. R. T.; GARCIA, R.; CARVALHO, M. M.; COUTO, L. Produção forrageira de gramíneas cultivadas sob luminosidade reduzida. Revista Brasileira de Zootecnia, Viçosa, MG, v. 28, n. 5, p. 919-927, 1999.

ERIKSEN, F. I.; WHITNEY, A. S. Effects of light intensity on growth of some tropical forage species. I: Interaction of light intensity and nitrogen fertilization on six forage grasses. Agronomy Journal, Madison, v. 73, n. 3, p. 427433, 1981 
EUCLYDES, R. F. Sistemas de análises estatísticas e genéticas (SAEG). Viçosa, MG: UFV, [1983?]. 68 p.

MAHECHA, L.; ROSALES, M.; MOLINA, C. H.; MOLINA, E. J. Un sistema silvopastoril de Leucaena leucocephala-Cynodon plectostachyus-Prosopis juliflora en el Valle del Cauca, Colombia. In: SANCHEZ, M. D.; ROSALES, M. (Ed.). Agroforestería para la producción animal en América Latina. Roma: FAO, 1999. p. $407-$ 419.

OLIVEIRA, P. R. P.; HUMPHREYS, L. R. Influence of level and timing of shading on seed production in Panicum maximum cv. Gatton. Australian Journal of Agricultural Research, Melbourne, v. 3, p. 417-424, 1986.

OVALLE, C.; AVENDAÑO, J. Influencia del árbol sobre la vegetación en los espinales (Acacia caven) de la zona mediterránea de Chile. In: CONGRESSO BRASILEIRO SOBRE SISTEMAS AGROFLORESTAIS, 1., 1994, Porto Velho. Anais... Colombo: Embrapa-CNPF, 1994. p. 151159. (Documentos, 27).

SAMARAKOON, S. P.; WILSON, J. R.; SHELTON, H. M. Growth, morphology and nutritive value of shaded Stenotaphrum secundatum, Axonopus compressus and
Pennisetum clandestinum. Journal of Agricultural Science, Cambridge, Inglaterra, v. 114, p. 161-169, 1990.

SOEST, P. J. van. Use of detergents in the analysis of fibrous feed. 1: Preparation of fiber residues of low nitrogen content. Journal of the Association of Official Agricultural Chemists, Washington, v. 46, p. 825-882, 1963.

TILLEY, J. M. A.; TERRY, R. A. A two-stage technique for the "in vitro" digestion of forage crop. Journal of the British Grassland Society, Hurley, v. 18, n. 2, p. 104$111,1963$.

WILSON, J. R.; WONG, C. C. Effects of shade on some factors influencing nutritive quality of green panic and Siratro pastures. Australian Journal of Agricultural Research, Melbourne, v. 33, n. 6, p. 937-949, 1982.

WONG, C. C. Shade tolerance of tropical forages. In: SHELTON, H. M.; STÜR, W. W. (Ed.). Forages for plantation crops. Canberra: ACIAR, 1991. p. 64-69. (ACIAR Proceedings, 32).

WONG, C. C.; WILSON, J. R. The effect of shade on the growth and nitrogen content of green panic and siratro in pure and mixed swards defoliated at two frequencies. Australian Journal of Agricultural Research, Melbourne, v. 31, p. 269-285, 1980. 